\title{
Endoluminal wound vac: an evolving role in treatment of esophageal perforation
}

\author{
Carolyn Baindu Moore ${ }^{1}$, Omar Almoghrabi ${ }^{1}$, Wayne Hofstetter ${ }^{2}$, Nirmal Veeramachaneni ${ }^{1}$ \\ ${ }^{1}$ Department of Cardiovascular and Thoracic Surgery, University of Kansas Medical Center, Kansas City, KS, USA; ${ }^{2}$ Department of Thoracic and \\ Cardiovascular Surgery, University of Texas MD Anderson Cancer Center, Houston, TX, USA \\ Contributions: (I) Conception and design: All authors; (II) Administrative support: W Hofstetter, N Veeramachaneni; (III) Provision of study \\ materials or patients: N Veeramachaneni; (IV) Collection and assembly of data: CB Moore; (V) Data analysis and interpretation: CB Moore, N \\ Veeramachaneni; (VI) Manuscript writing: All authors; (VII) Final approval of manuscript: All authors. \\ Correspondence to: Nirmal Veeramachaneni, MD. Department of Cardiovascular and Thoracic Surgery, University of Kansas Medical Center, Kansas \\ City, KS, USA. Email: nveeramachaneni@kumc.edu.
}

\begin{abstract}
The treatment of esophageal leaks and perforations has evolved over time with the advancement of technology. Compared to traditional surgical intervention, newer less invasive options such as stents can be effective with less morbidity. The latest addition to the surgeon's armamentarium, endoluminal wound vac therapy (EVT), uses the principle of negative pressure wound therapy to heal leaks and perforations.
\end{abstract}

Keywords: Endoluminal wound vac therapy (EVT); esophageal leak; esophageal perforation

Received: 03 January 2020; Accepted: 16 February 2020; Published: 05 October 2020.

doi: 10.21037 /jovs.2020.01.04

View this article at: http://dx.doi.org/10.21037/jovs.2020.01.04

\section{Treatment options of esophageal perforation/ leaks}

Esophageal leaks and perforations span a spectrum of severity. Whether benign or malignant, leaks and perforations are caused by a transmural disruption of the esophagus (1). Most esophageal perforations are iatrogenic and occur during diagnostic and endoscopic procedures (2). Boerhaave syndrome represents a perforation caused by an abrupt increase in the esophageal pressure following emesis in the absence of relaxation of the superior esophageal sphincter (3-5). It was first described by the Dutch physician Herman Boerhaave. Boerhaave presented the autopsy findings of Baron von Wassenaer, Grand Admiral of the Fleet of Holland (6,7). von Wassenaer presented to Boerhaave after a night of overeating, several episodes of emesis, and chest pain. In Boerhaave's report, he described classic features noted in esophageal perforations including mediastinal emphysema and contamination of the pleural fluid $(6,7)$.

Leaks and perforations can be diagnosed by chest X-ray
(CXR). However, the gold standard study remains contrast esophagram using a water-soluble medium that may have to be followed by a barium study if the initial result is negative. If there is an issue with performing an esophagram, the alternative is a contrast-enhanced computed tomography $(\mathrm{CT})$ scan $(8,9)$. Signs of perforation and leaks include mediastinal air, extravasated luminal contrast, periesophageal fluid collections, and pleural effusions $(8,9)$. An endoscopic procedure is also recommended for confirmatory diagnosis as well as diagnostic decision making $(8,9)$. The treatment options for esophageal leaks and perforations are associated with considerable morbidity and mortality (10). Based on work dating back to 1936, Jemerin was the first to confirm that drainage surgery should be the standard for leaks and perforations. Studies before this time showed that no surgical treatment would lead to significant death in twenty-four hours (11). Most of these drainage procedures occurred in the neck, and perforations were due to iatrogenic causes. Collis, in 1944, was the first to perform a thoracotomy for rupture $(12,13)$. Barrett, Olsen, and Clagett presented other studies to confirm the importance 
of early surgical treatment (13-16).

The present-day treatment algorithm consists of empiric antibiotics, including antifungal therapy, enteral nutrition, drainage of fluid collections, and management of the perforation/leak. Management options to consider are stent placement, T-tube, excision and diversion, and primary repair (17). Freeman et al. published such an algorithm based on their institution's experience with esophageal perforations and stent placement (18). D'Cunha et al. also created an esophageal treatment algorithm and concluded that the success of these patients depends on appropriate procedures for source control and surgeon experience (19). The choice of treatment modality is weighed heavily and is dependent upon the cause, location, size of the defect, hemodynamic status, and time from the event. Stents tend to be less effective, for more chronic perforations. One minimally invasive option, stents, is an effective surgical option with shorter length of stay, lower rates of morbidity, and lower costs; however, stents can migrate and erode adjacent structures (18,20-24). Freeman and colleagues have published comprehensive reports on the usage of esophageal stents $(18,22-24)$.

Another option, the use of a T-tube, is time intensive because the esophagus has no mesentery and no mesothelial cells to seal the defect. Closure is dependent upon healing around the site of defect, and proper lung expansion to close the resulting tract, similar to the management of a biliary t-tube application (25). Linden et al. in 2003, presented results from an extensive series of patients with delayed intrathoracic perforations at Brigham and Women's over 13 years. Most acute thoracic esophageal perforations were treated with primary repair. Linden and colleagues concluded that treatment of delayed (more than 24 hours) thoracic esophageal perforations with a controlled fistula through T-tube results in a very low mortality similar to that seen with acute perforations (less than 24 hours). However, morbidity and length of stay remain high (26). Minimally invasive options such as stents and t-tubes do not preclude the need for multiple operations to treat underlying empyema or to obtain enteral access. Alternative strategies such as esophageal excision, and diversion have substantial post-op morbidity and mortality (10). Endoluminal wound vac therapy (EVT) provides a novel alternative to these options that is also non-invasive and successful (17).

\section{Mechanism of action of EVT}

The EVT is negative pressure wound therapy (NPWT) applied to the gastrointestinal (GI) tract. NPW'T is a process that involves the placement of a porous material into a wound which is connected to a drainage port that is sealed tightly with adhesive. The drainage port attaches to a controlled vacuum pump that applies negative pressure (27-29). The suction leads to primary and secondary wound effects. The primary effects are macrodeformation and microdeformation of the wound, fluid removal, alteration of the wound environment and debridement (30). Macrodeformation is wound shrinkage when applying suction to the foam, which results in deformational forces applied on the wound edges, which draws them together $(31,32)$. Animal model studies demonstrate a decrease in the volume of foam by approximately $80 \%$ resulting in smaller wound size from macrodeformation $(31,32)$. Microdeformation is the mechanical changes that occur on the microscopic level when suction is applied. NWPT is also known to remove fluid accumulation (33). Debridement removes the nonviable tissue from the wound. The alteration of the wound environment from macrodeformation, microdeformation, debridement and fluid removal results in secondary effects: neurogenesis, angiogenesis, hemostasis, and modulation of inflammation (33). The use of NPWT varies and is indicated in grafts, flaps, chronic and acute wounds, and burns (34). The commercial usage of NPWT by KCI (Kinetic Concepts Inc., TX USA) was approved in 1995 after decades of research done in animal and human models. The application of NPWT to the GI tract would follow suit, and the first usage of EVT was described by Weidenhagen $e t$ al. in a case series for rectal anastomotic leaks (35). A few years later, the applications to upper GI defects ensued (36,37).

\section{Indications and contraindications of EVT}

EVT has been described in the majority of GI complications that range from small defects, large defects, small bowel, biliopancreatic, colorectal, gastric, and esophageal complications (38-41). Contraindications to EVT are unclear. Users should avoid placement close to major vessels, and defects in connection to the tracheobronchial system $(27,42-45)$.

\section{EVT appliance composition}

There are different types of foams used: open-pore polyurethane-foam (OPD), OPD coated with open-pore film (OPFD), or the open-pore film drain. OPD are active drains that can work against gravity pressure gradient (46). 


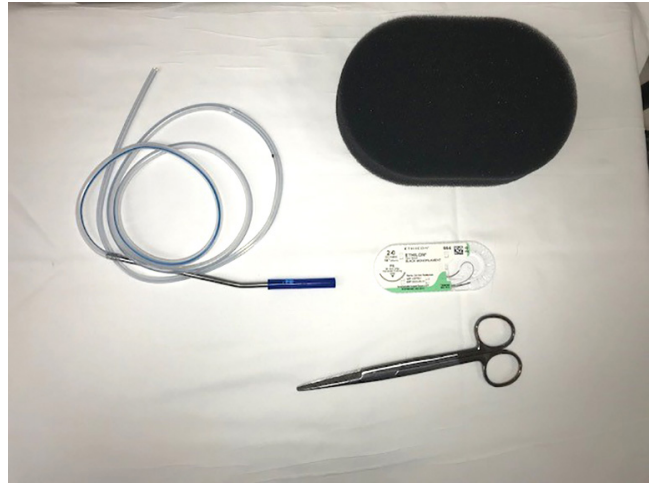

Figure 1 An alternative set-up for EVT. From left to right: blake drain, black sponge, 2-0 ethilon suture, and scissors. EVT, endoluminal wound vac therapy.

They differ from conventional passive drains, which uses gravity to drain fluids along a favorable pressure gradient or capillary pressure. The foams are all polyurethane and densely packed with pore openings. There are several variables involved in suction firmness and tightness of the foam to wound bed. These variables are pore size, foam surface, and the consistency of the wound surface; they can be suctioned very firmly to the wound bed and accordingly adhere tightly. When negative pressure is applied under suction, the foam pores become adherent to the wound bed resulting in collapsing of the wound cavity and intestinal lumen around the polyurethane foam. These actions lead to fibrin deposition, epithelialization, secondary wound closure of the defect (46).

\section{EVT set-up}

EVT can be performed under general anesthesia after the airway is protected by endotracheal intubation or under monitored sedation. Our preference was general anesthesia. We use a standard gastroscope with a diameter of $10 \mathrm{~mm}$ with an instrument channel of $2.8 \mathrm{~mm}$. We utilize either a 16-18 Fr nasogastric tube (NGT), or a shortened blake drain (Figure 1). The NGT or blake drain should be modified and trimmed so that all suction passes though the sponge. This is critical to success of the technique. The EVT is created by first cutting the OPD to a suitable width. A tunnel is created through its center to the tip without exiting the sponge (47). The NGT is then placed into this tunnel to encompass the fenestrations in the NGT. A nonabsorbable monofilament is used to secure the sponge to NGT. Another suture is used through the sponge to create an air knot. This knot is used to grasp the EVT with forceps and facilitate carrying it into place. The gastroscope is introduced into the mouth with the forceps in the channel, grasping the EVT at the air knot. Both the EVT and endoscope are advanced together into the esophagus, and the EVT is left in place covering the defect. Another option used by one of the authors is the placement of an EVT followed by stent placement to anchor the EVT in place. This mechanism keeps the lumen open while simultaneously facilitating the apposition of the sponge to the esophageal mucosa for a tight seal. During removal, the endoscope is used to dislodge the foam with gentle forward pressure and irrigation with saline. Once dislodged, the EVT is pulled up to the oropharynx and cut from the NGT through the mouth before removing the rest of the NGT through the nose (47). Most of the literature advocates exchange of the sponge every few days, but with increasing experience, we have increased the interval of EVT to change to every 7-10 days (Figure 2).

The accompanying video (Video 1) demonstrates the setup of the endoluminal wound vac. In a patient, the nasogastric would be first passed through the nare, and brought out through the mouth. Once brought out through the mouth, the NGT is trimmed to eliminate the extra venting holes, and the sponge is secured in place with prolene suture. A blake drain, appropriately trimmed, may also be used.

\section{Supporting data for EVT}

The use of EVT has been described in many single center retrospective case series. Schorsch et al. performed a retrospective cohort study of thirty-five patients that used EVT for anastomotic leaks and iatrogenic perforations. The majority of these patients had an anastomotic leakage. The anastomotic leak healed in $95.2 \%$ of their patients with a median treatment duration of 11 days. Patients with iatrogenic injuries had a $100 \%$ healing of injury with a median treatment time of 5 days (48). Schorsch's study supports the safe and effective use in esophageal leaks and perforations (48). Another retrospective cohort study by Bludau et al. demonstrates the effectiveness of EVT as part of a multimodality approach (44). Results showed a complete restoration of the esophageal defect in $86 \%$ of their patients with the average duration of application being 12.1 days $(25,44)$. EVT and self-expanding metal stents were used in combination with $42 \%$ of their patients. Laukoetter and colleague highlights 


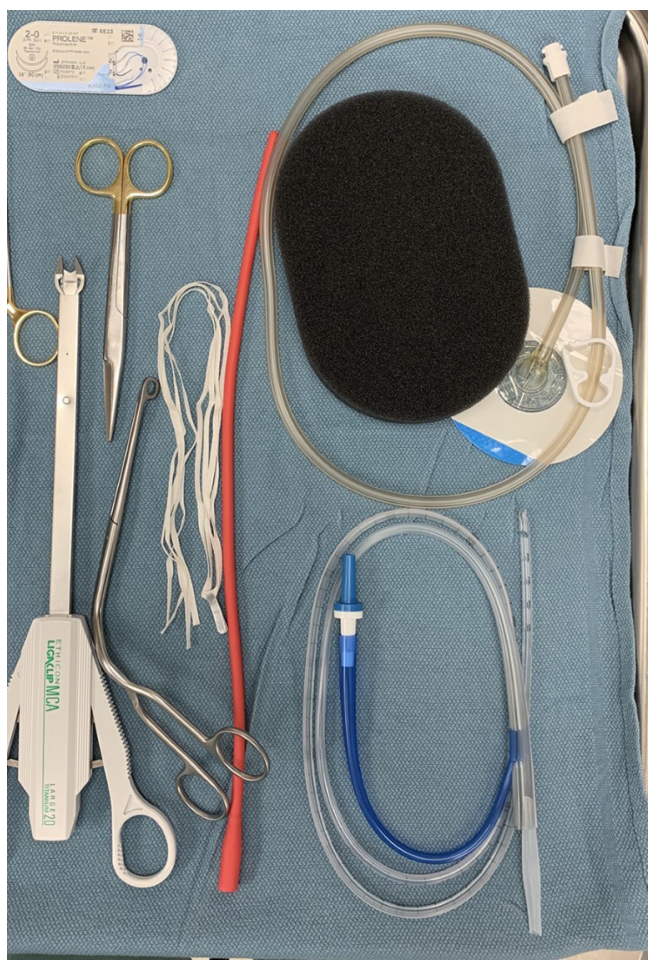

Figure 2 Our preferred strategy of instruments and supplies needed to set-up EVT. From left to right and top to bottom: 3-0 prolene suture, stapler, scissor, McGill forceps, umbilical tape, red rubber catheter, black wound vacuum sponge with suction appliance and a 16-18 French NGT. The red rubber catheter and umbilical tape are used to bridle the NGT at the nose. EVT, endoluminal wound vac therapy; NGT, nasogastric tube.

the possible complications of EVT application. Fifty-two patients were included in the study. EVT failed in $6 \%$ of the patients. The EVT was changed at an interval of 3 to 5 days. The defect healed in $94.2 \%$. Two patients died due to hemorrhage related to EVT. One patient had an acute hemorrhage related to EVT and subsequent intracranial hemorrhage and cardiac infarction that lead to death (43). The second patient died from hemorrhage during the third EVT change while inserting a new appliance (43). Stricture complication occurred in $7 \%$ of the patients (43). Wedemeyer et al. was a prospective study that used EVT in eight consecutive leak patients. Success was noted in $88 \%$ of the leaks with no significant complications (49). A more extensive study of 366 patients by Schniewind et al. showed the superiority of EVT to other modalities. In systemically ill patients with an APACHE II score mean of 14.4, EVT patients had lower mortality of (12\%)

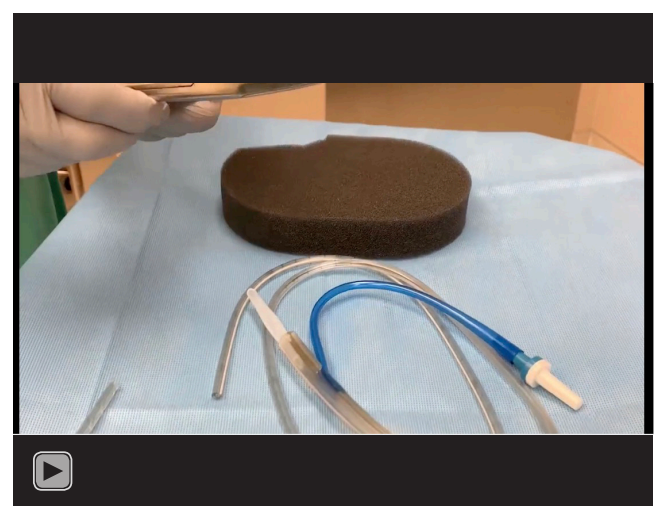

Video 1 The setup of the endoluminal wound vac.

compared to surgically treated patients $(50 \%, \mathrm{P}=0.01)$ and patients managed by stent placement $(83 \%, \mathrm{P}=00014)(50)$. Overall, the research is promising on the use of EVT in the management of esophageal leaks and perforations (50).

Neuman and colleagues attempted to apply EVT to esophagectomy patients in whom the anastomosis was deemed to be ischemic and at risk of leak. They noted encouraging results with 2 of 8 patients developing a leak, and also those patients with a leak using EVT (51). Esophageal complications noted in literature amenable to EVT are leaks, perforation, and ischemic conduits $(46,51,52)$.

\section{Case report}

To illustrate the utility of EVT we present the case of a 62-year-old male diagnosed with T-cell Acute Lymphocytic Leukemia and treated with chemotherapy who presented to an outside hospital with upper respiratory infection. A CT scan of his chest demonstrated a left suprahilar lung consolidation for which he was treated with antibiotics. However, his symptoms worsened. He presented again to the hospital with hemoptysis and dyspnea. A repeat CT scan of the chest showed worsening inflammatory changes to the left suprahilar consolidation with associated necrotic mass versus abscess of the mediastinum (Figure 3). Blood cultures were positive for Bacteroides fragilis. An esophagogastroduodenoscopy (EGD) with biopsy was performed which showed a small upper esophageal perforation. The esophageal biopsy showed chronic active inflammation, presence of acute fibroinflammatory exudate and granulation tissue with degenerated fungal organisms morphologically suggestive of Candida species. A few 


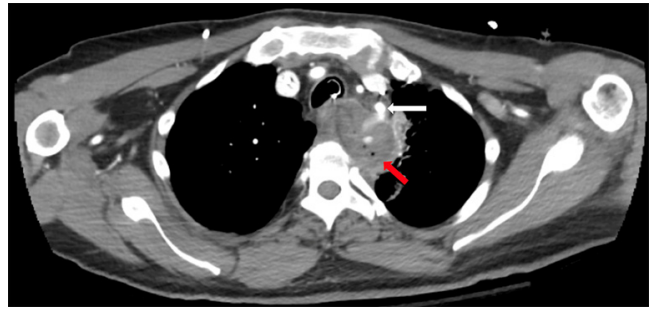

Figure 3 Axial CT image demonstrating left suprahilar inflammatory changes (red arrow) seen next to the left subclavian artery (white arrow). CT, computed tomography.

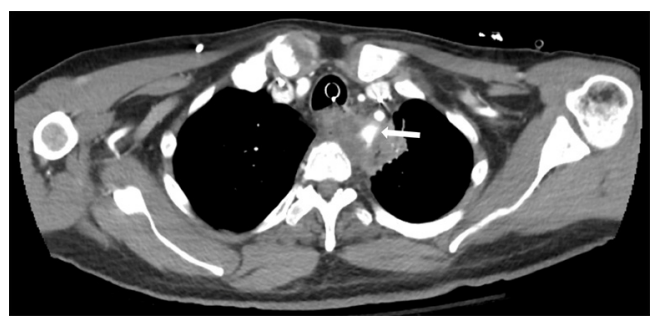

Figure 4 Axial CT image demonstrating left suprahilar inflammatory changes with extravasation from the left subclavian artery (arrow). CT, computed tomography.

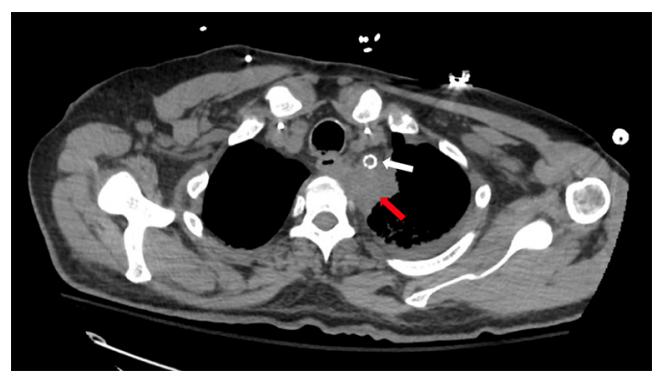

Figure 5 Axial CT image demonstrating left suprahilar inflammatory changes (red arrow) with a stent in the left subclavian artery (white arrow). CT, computed tomography.

days later, the patient had large amounts of hematemesis. On CT angiography of the chest, he was found to have a pseudoaneurysm of left subclavian artery with extravasation into the area of concern (Figure 4). He underwent emergent angioplasty and stenting of the left subclavian (Figure 5). An esophagram was performed which demonstrated a contained leak of the thoracic esophagus via $1.3-\mathrm{cm}$ diameter defect with no extension into the pleural space or pulmonary parenchyma. A feeding gastrostomy tube was placed, and the patient was kept nil per os (NPO). The patient was then

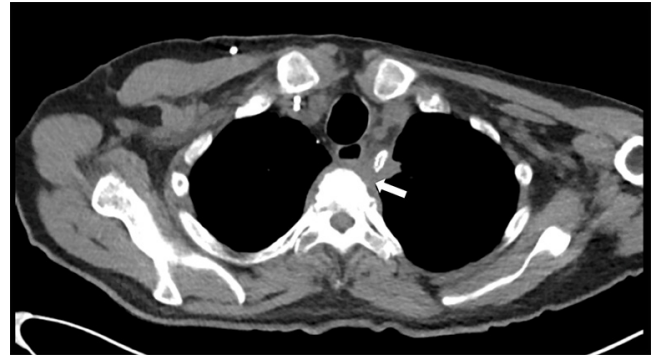

Figure 6 Axial CT image 3 months after EVT treatments demonstrating near complete resolution of the left suprahilar inflammatory changes (arrow). EVT, endoluminal wound vac therapy; CT, computed tomography.

transferred to our facility for further care of this complex upper esophageal perforation caused by lung abscess.

Upon transfer, an EGD was performed which showed a disruption of the esophagus into a blind pouch. In this immunocompromised patient, an infection in the left upper lobe led to a mediastinal phlegmon and erosion into vascular structures and the esophagus. Upon reviewing his risks factors and co-morbidities, an esophageal diversion with possible reconstruction of the subclavian artery was deemed high risk. However, due to the concern for the phlegmon and associated inflammatory changes causing erosion in the vessels, an intervention was warranted. He underwent a total of five EVT changes, done every other day. Each session demonstrated gradual improvement on EGD. He was discharged home on gastric tube feeds, antibiotics and kept NPO for 12 weeks. He was seen in the clinic and his diet was advanced slowly after CT scan revealed near resolution of the inflammatory changes (Figure 6).

\section{Conclusions}

Esophageal leaks and perforations have devastating consequences if not treated in a timely fashion. There are multiple invasive and non-invasive modalities used to control leaks and perforations. Retrospective data are encouraging in the use of EVT for this life-threatening complication. Excellent patient outcomes have been noted in the treatment of iatrogenic injuries, with $100 \%$ healing rates (37). The acuity of the patient varied cross studies; some patients were reportedly critically ill (50). EVT has even been noted to work as well as stents or seen to be superior to stent placement $(20,21,37)$. It has also been shown to function as a bridge to other modalities such as surgery (53). The most severe complication published from 
EVT usage is bleeding, though rare overall (43).

The decision to use EVT in the treatment algorithm at times can be challenging; there are no standard guidelines to follow. We recommend against the use of EVT in patients deemed unstable or have multi-organ failure (54). Clinically unstable patients should proceed to surgery. Also, EVT can be utilized by itself or in combination with other treatment modalities based on the surgeon's discretion. The tenants of leaks must be upheld overall: control ongoing leakage, drain the contaminated space, treat with antibiotics and ensure adequate nutrition.

The choice between T-tube, stent, and EVT is less clear. We avoid stent placement near the upper esophageal sphincter, lower esophageal sphincter injuries spanning the gastroesophageal junction and for long segment injuries (55-59). T-tubes have a role for injuries that cannot be repaired primarily, especially those presenting in a delayed manner. In our own practice, we have utilized EVT as an alternative to the T-tube method, when a stent is not feasible. In general, we do not advise placement of EVT near vessels and tracheobronchial system (27,42-45). EVT presents as an alternative option for esophageal leaks and perforations. Further studies are needed to define the limitations of EVT, its optimal role, and perhaps its utilization to prevent esophageal anastomotic disruption.

\section{Acknowledgments}

Funding: None.

\section{Footnote}

Conflicts of Interest: All authors have completed the ICMJE uniform disclosure form (available at https://jovs. amegroups.com/article/view/10.21037/jovs.2020.01.04/ coif). The authors have no conflicts of interest to declare.

Ethical Statement: The authors are accountable for all aspects of the work in ensuring that questions related to the accuracy or integrity of any part of the work are appropriately investigated and resolved.

Open Access Statement: This is an Open Access article distributed in accordance with the Creative Commons Attribution-NonCommercial-NoDerivs 4.0 International License (CC BY-NC-ND 4.0), which permits the noncommercial replication and distribution of the article with the strict proviso that no changes or edits are made and the original work is properly cited (including links to both the formal publication through the relevant DOI and the license). See: https://creativecommons.org/licenses/by-nc-nd/4.0/.

\section{References}

1. Sdralis EIK, Petousis S, Rashid F, et al. Epidemiology, diagnosis, and management of esophageal perforations: systematic review. Dis Esophagus 2017;30:1-6.

2. Baron TH, Wong Kee Song LM, Zielinski MD, et al. A comprehensive approach to the management of acute endoscopic perforations (with videos). Gastrointest Endosc 2012;76:838-59.

3. Chirica M, Champault A, Dray X, et al. Esophageal perforations. J Visc Surg 2010;147:e117-28.

4. Aloreidi K, Patel B, Ridgway T, et al. Non-surgical management of Boerhaave's syndrome: a case series study and review of the literature. Endosc Int Open 2018;6:E92-7.

5. Korn O, Onate JC, Lopez R. Anatomy of the Boerhaave syndrome. Surgery 2007;141:222-8.

6. Boerhaave H. Atrocis nec decscripti pruis morbi historica. Secondum Medicae Artis Leges Conscripta. Lugd. Bat. Bontesteniana, 1724. Translated in Bull. Med Libra Ass 1955;43:217.

7. Lindeboom GA. Herman Boerhaave (1668-1738). Teacher of all Europe. JAMA 1968;206:2297-301.

8. Maniatis V, Chryssikopoulos H, Roussakis A, et al. Perforation of the alimentary tract: evaluation with computed tomography. Abdom Imaging 2000;25:373-9.

9. Backer CL, LoCicero J 3rd, Hartz RS, et al. Computed tomography in patients with esophageal perforation. Chest 1990;98:1078-80.

10. Salo JA, Isolauri JO, Heikkila LJ, et al. Management of delayed esophageal perforation with mediastinal sepsis. Esophagectomy or primary repair? J Thorac Cardiovasc Surg 1993;106:1088-91

11. Jemerin EE. Results of Treatment of Perforation of the Esophagus. Ann Surg 1948;128:971-5.

12. Derbes VJ, Mitchell RE Jr. Rupture of the esophagus. Surgery 1956;39:865-88.

13. Collis JL. Humphreys DR, Bond WH. Spontaneous rupture of the esophagus. Lancet 1944;2:179.

14. Barrett NR. Spontaneous perforation of the oesophagus; review of the literature and report of three new cases. Thorax 1946;1:48-70.

15. Barrett NR. Report of a case of spontaneous perforation of the oesophagus successfully treated by operation. Br J Surg 
1947;35:216-8.

16. Olsen AM, Clagett OT. Spontaneous rupture of the esophagus; report of a case with immediate diagnosis and successful surgical repair. Postgrad Med 1947;2:417-21.

17. Gonzalez JM, Servajean C, Aider B, et al. Efficacy of the endoscopic management of postoperative fistulas of leakages after esophageal surgery for cancer: a retrospective series. Surg Endosc 2016;30:4895-903.

18. Freeman RK, Ascioti AJ, Giannini T, et al. Analysis of unsuccessful esophageal stent placements for esophageal perforation, fistula, or anastomotic leak. Ann Thorac Surg 2012;94:959-64; discussion 964-5.

19. D'Cunha J, Rueth NM, Groth SS, et al. Esophageal stents for anastomotic leaks and perforations. J Thorac Cardiovasc Surg 2011;142:39-46.e1.

20. Mennigen R, Harting C, Lindner K, et al. Comparison of Endoscopic Vacuum Therapy Versus Stent for Anastomotic Leak After Esophagectomy. J Gastrointest Surg 2015;19:1229-35.

21. Hwang JJ, Jeong YS, Park YS, et al. Comparison of Endoscopic Vacuum Therapy and Endoscopic Stent Implantation With Self-Expandable Metal Stent in Treating Postsurgical Gastroesophageal Leakage. Medicine (Baltimore) 2016;95:e3416.

22. Freeman RK, Herrera A, Ascioti AJ, et al. A propensitymatched comparison of cost and outcomes after esophageal stent placement or primary surgical repair for iatrogenic esophageal perforation. J Thorac Cardiovasc Surg 2015;149:1550-5.

23. Freeman RK, Van Woerkom JM, Ascioti AJ. Esophageal stent placement for the treatment of iatrogenic intrathoracic esophageal perforation. Ann Thorac Surg 2007;83:2003-7; discussion 2007-8.

24. Freeman RK, Ascioti AJ, Wozniak TC. Postoperative esophageal leak manage- ment with the Polyflex esophageal stent. J Thorac Cardiovasc Surg 2007;133:333-8.

25. Ojima H, Kuwano H, Sasaki S, et al. Successful late management of spontaneous esophageal rupture using T-tube mediastinoabdominal drainage. Am J Surg 2001;182:192-6.

26. Linden PA, Bueno R, Mentzer SJ, et al. Modified T-tube repair of delayed esophageal perforation results in a low mortality rate similar to that seen with acute perforations. Ann Thorac Surg 2007;83:1129-33.

27. Ahrens M, Schulte T, Egberts J, et al. Drainage of esophageal leakage using endoscopic vacuum therapy: a prospective pilot study. Endoscopy 2010;42:693-8
28. Huang C, Leavitt T, Bayer LR, et al. Effect of negative pressure wound therapy on wound healing. Curr Probl Surg 2014;51:301-31.

29. Malmsjö M, Borgquist O. NPWT settings and dressing choices made easy. Wounds International 2010;1:1-6.

30. Panayi AC, Leavitt T, Orgill DP. Evidence based review of negative pressure wound therapy. World J Dermatol 2017;6:1-16.

31. Scherer SS, Pietramaggiori G, Mathews JC, et al. The mechanism of action of the vacuum-assisted closure device. Plast Reconstr Surg 2008;122:786-97.

32. Borgquist $\mathrm{O}$, Ingemansson $\mathrm{R}, \mathrm{Malmsjö} M$. The influence of low and high-pressure levels during negative-pressure wound therapy on wound contraction and fluid evacuation. Plast Reconstr Surg 2011;127:551-9.

33. Argenta LC, Morykwas MJ. Vacuum-assisted closure: a new method for wound control and treatment: clinical experience. Ann Plast Surg 1997;38:563-76; discussion 577.

34. V.A.C.s Therapy Forms and Brochures. Available online: http://www.kcimedical.co.uk/UKENG/ vacformsandbrochures

35. Weidenhagen R, Gruetzner KU, Wiecken T, et al. Endoscopic vacuum-assisted closure of anastomotic leakage following anterior resection of the rectum: a new method. Surg Endosc 2008;22:1818-25.

36. Smallwood NR, Fleshman JW, Leeds SG, et al. The use of endoluminal vacuum (E-Vac) therapy in the management of upper gastrointestinal leaks and perforations. Surg Endosc 2016;30:2473-80.

37. Kuehn F, Loske G, Schiffmann L, et al. Endoscopic vacuum therapy for various defects of the upper gastrointestinal tract. Surg Endosc 2017;31:3449-58.

38. de Moura DTH, Sachdev AH, Thompson CC. Endoscopic Full-Thickness Defects and Closure Techniques. Curr Treat Options Gastroenterol 2018;16:386-405.

39. Dhayat SA, Schacht R, Mennigen R, et al. Long-Term Quality of Life Assessment After Successful Endoscopic Vacuum Therapy of Defects in the Upper Gastrointestinal Tract Quality of Life After EVT. J Gastrointest Surg 2019;23:280-7.

40. Knoop RF, Thimme R, Fischer A. Successful twosided sponge pull-through treatment of anastomotic leakage following pancreaticoduodenectomy with pancreaticogastrostomy. Endoscopy 2017;49:1010-2

41. Borstlap WAA, Musters GD, Stassen LPS, et al. Vacuum-assisted early transanal closure of leaking low colorectal anastomoses: the CLEAN study. Surg Endosc 2018;32:315-27. 
42. Loske G, Müller CT. Tips and tricks for endoscopic negative pressure therapy. Tipps und Tricks in der endoskopischen Unterdruck Therapie. Chirurg 2019;90:7-14.

43. Laukoetter MG, Mennigen R, Neumann PA, et al. Successful closure of defects in the upper gastrointestinal tract by endoscopic vacuum therapy (EVT): a prospective cohort study. Surg Endosc 2017;31:2687-96.

44. Bludau M, Hölscher AH, Herbold T, et al. Management of upper intestinal leaks using an endoscopic vacuum-assisted closure system (E-VAC). Surg Endosc 2014;28:896-901

45. Pournaras DJ, Hardwick RH, Safranek PM, et al. Endoluminal Vacuum Therapy (E-Vac): A Treatment Option in Oesophagogastric Surgery. World J Surg 2018;42:2507-11.

46. Newton NJ, Sharrock A, Rickard R, et al. Systematic review of the use of endo-luminal topical negative pressure in oesophageal leaks and perforations. Dis Esophagus 2017;30:1-5.

47. Leeds SG, Burdick JS. Management of gastric leaks after sleeve gastrectomy with endoluminal vacuum (E-Vac) therapy. Surg Obes Relat Dis 2016;12:1278-85.

48. Schorsch T, Müller C, Loske G. Endoscopic Vacuum Therapy of Perforations and Anastomotic Insufficiency of the Esophagus. Chirurg 2014;85:1081-93.

49. Wedemeyer J, Brangewitz M, Kubicka S, et al. Management of major postsurgical gastroesophageal intrathoracic leaks with an endoscopic vacuum-assisted closure system. Gastrointest Endosc 2010;71:382-6.

50. Schniewind B, Schafmayer C, Voehrs G, et al. Endoscopic endoluminal vacuum therapy is superior to other regimens in managing anastomotic leakage after esophagectomy: a comparative retrospective study. Surg Endosc

doi: 10.21037/jovs.2020.01.04

Cite this article as: Moore CB, Almoghrabi O, Hofstetter W, Veeramachaneni N. Endoluminal wound vac: an evolving role in treatment of esophageal perforation. J Vis Surg 2020;6:43.
2013;27:3883-90.

51. Neumann PA, Mennigen R, Palmes D, et al. Pre-emptive endoscopic vacuum therapy for treatment of anastomotic ischemia after esophageal resections. Endoscopy 2017;49:498-503.

52. Manfredi MA, Clark SJ, Staffa SJ, et al. Endoscopic Esophageal Vacuum Therapy: A Novel Therapy for Esophageal Perforations in Pediatric Patients. J Pediatr Gastroenterol Nutr 2018;67:706-12.

53. Scott RB, Ritter LA, Shada AL, et al. Endoluminal vacuum therapy for Ivor lewis anastomotic leaks: a pilot study in a swine model. Clin Transl Sci 2017;10:35-41.

54. Price TN, Nichols FC, Harmsen WS, et al. A comprehensive review of anastomotic technique in 432 esophagectomies. Ann Thorac Surg 2013;95: Price TN, Nichols FC, Harmsen WS, et al. A comprehensive review of anastomotic technique in 432 esophagectomies. Ann Thorac Surg 2013;95:1154-60; discussion 1160-1.

55. ASGE Standards of Practice Committee, Lee KK, Anderson MA, et al. Modifications in endoscopic practice for pediatric patients. Gastrointest Endosc 2008;67:1-9.

56. Gislason GT, Pasricha PJ. Crossing the upper limit: esophageal stenting in the proximal esophagus. Dysphagia 1997;12:84-5.

57. Verschuur EM, Kuipers EJ, Siersema PD. Esophageal stents for malignant strictures close to the upper esophageal sphincter. Gastrointest Endosc 2007;66:1082-90.

58. Dua KS, Kozarek R, Kim J, et al. Self-expanding metal esophageal stent with anti-reflux mechanism. Gastrointest Endosc 2001;53:603-13.

59. Ong GKB, Freeman RK. Endoscopic management of esophageal leaks. J Thorac Dis 2017;9:S135-45. 